\title{
Influence and optimization criterion of milling modes and process parameters on residual stress
}

\author{
Beizhi Li ${ }^{1, a}$, Yingzi Yan ${ }^{1, b^{*}}$ and Jianguo Yang ${ }^{1, c}$ \\ ${ }^{1}$ Donghua University, Shanghai, China \\ a Ibzhi@dhu.edu.cn, ${ }^{\mathrm{b}}$ yingziyan06@163.com, ${ }^{\mathrm{c}}$ jgyangm@dhu.edu.cn
}

Keywords: Residual stress; Milling mode; process parameters; Finite element simulation; optimization criterion.

Abstract. The reduction and control of residual stress is very important to improve the surface quality and machining accuracy of the parts. In this paper, in order to reveal the effects of different milling modes and process parameters on the residual stress, the aluminum alloy A17050-T7451 is used as the machining object and the finite element simulation software AdvantEdge is applied in establishing the milling model. It is found that up-milling is better than down-milling in low-speed and there is no obvious difference between them in high-speed. Besides, high-speed machining can obtain the smaller depth of sub-surface residual stress. Compared with low-speed, high-speed is more advantageous to realize the unification of quality and efficiency. What's more, decreasing cutting width and improving cutting depth is easy to obtain ideal residual stress when the material removal rate is constant. Experiments on up-milling and down-milling have verified the validity of the finite element model and the effects of milling modes and process parameters on the residual stress. It has laid a solid theoretical and practical basis for constructing process optimization criteria, choosing appropriate milling modes and optimizing process parameters.

\section{Introduction}

Surface residual stress has an extremely important impact on the performance of the parts. Residual tensile stress can severely reduce the fatigue strength of parts. When the residual stress distribution is not uniform, it will result in distortion of parts which seriously affect shape accuracy and dimensional accuracy. Obviously, how to control the residual stress is very important to guarantee the surface quality and improve life time of parts.

A large number of studies on the residual stress have been carried out by scholars around the world. Coto.B [1] analyzed the effect of feed speed and spindle speed on the residual stress. Capello E [2] used the method of X-ray to study the impact of cutting depth on the residual stress. Ee K C [3] established a thermal elastic-viscoplastic finite element model to analyze the influence of tool edge radius on residual stress. Thiele J D [4] conducted experiments to explore the influence of tool rake Angle on the residual stress. Li BZ, Jing X H [5, 6] set up a two-dimensional removal model to optimize spindle speed and cutting depth.

All these studies did not consider the effect of different milling modes on residual stress. Hadi M A [7] only discussed the difference between up-milling and down-milling on tool wear. Therefore, we set up three-dimensional milling model with AdvantEdge to explore the influence of different milling modes on residual stress distribution under the conditions of different process parameters. Besides, based on simulations, process parameters were optimized to control the residual stress. Finally, the finite element simulation results were verified by experiments.

\section{Construction of three dimensional milling model}

Metal cutting is a plastic deformation process with large strain, high temperature and high strain rate. It has an important influence on the residual stress distribution. A more consistent with actual tool structure model can be established in AdvantEdge and it can improve the calculation accuracy. 
Material constitutive equation. The constitutive relation of material is related to the strain, strain rate, temperature and other factors. Choosing the appropriate constitutive equation is the key to study the cutting deformation. Power Law is used in this simulation, as shown in Eq.1.

$$
\sigma\left(\varepsilon^{\mathrm{p}}, \& \& \mathrm{~T}\right)=\mathrm{g}\left(\varepsilon^{\mathrm{p}}\right) \cdot \Gamma(\varepsilon \& \cdot \Theta(\mathrm{T})
$$

Where $g\left(\varepsilon^{p}\right)$ is strain hardening coefficient, $\Gamma(\&)$ is strain-rate sensitivity, $\Theta(T)$ is thermal softening function.

Mesh generation technique. AdvantEdge adopts adaptive mesh refinement technique. Coarse mesh is used in non-cutting area, while fine mesh is used in cutting area. The mesh density from the non-cutting area to the cutting area presents gradient change. It ensures the accuracy of the simulation results and improves the computational efficiency. The maximum element size of tool is $1 \mathrm{~mm}$ and the minimum element size of tool is $0.02 \mathrm{~mm}$. The mesh size change of workpiece is consistent with the setting of tool.

Process parameter Settings. In this paper, the workpiece material is Al7050-T7451. The tool material is horniness alloy and its main parameters are diameter $12 \mathrm{~mm}$, helix angle $30^{\circ}$, rake angle $15^{\circ}$, clearance angle $6^{\circ}$, edge radius $0.04 \mathrm{~mm}$, cutter teeth is 4 . The initial environmental temperature is set to $20^{\circ} \mathrm{C}$. Milling parameters are shown in Table 1. Down-milling and up-milling have carried out in every case in order to explore the influence of different milling mode on the residual stress under different process parameters. In Table 1, case 1,2, 3 are low-speed with the same material removal rate. Case 4, 5, 6 are high-speed and the material removal rate is constant.

Table 1 process parameters

\begin{tabular}{|c|c|c|c|c|c|c|}
\hline Case & $\begin{array}{c}\text { Milling } \\
\text { mode }\end{array}$ & $\begin{array}{c}\text { Cutting } \\
\text { speed } n \\
{[\mathrm{rev} / \mathrm{min}]}\end{array}$ & $\begin{array}{c}\text { Feed } \\
{[\mathrm{mm} / \mathrm{rev}]}\end{array}$ & $\begin{array}{c}\text { Cutting } \\
\text { width } \\
a_{e}[\mathrm{~mm}]\end{array}$ & $\begin{array}{c}\text { Cutting } \\
\text { depth } \\
a_{p}[\mathrm{~mm}]\end{array}$ & $\begin{array}{c}\text { Removal rate } \\
\mathrm{Q}\left[\mathrm{mm}^{3} / \mathrm{min}\right]\end{array}$ \\
\hline 1 & down/up & 4000 & 0.8 & 10 & 0.12 & 3480 \\
\hline 2 & down/up & 4000 & 0.8 & 8 & 0.15 & 3480 \\
\hline 3 & down/up & 4000 & 0.8 & 6 & 0.12 & 3480 \\
\hline 4 & down/up & 18000 & 0.8 & 10 & 0.12 & 17280 \\
\hline 5 & down/up & 18000 & 0.8 & 8 & 0.15 & 17280 \\
\hline 6 & down/up & 18000 & 0.8 & 6 & 0.2 & 17280 \\
\hline
\end{tabular}

\section{Finite element simulation results and analysis}

The residual stresses extraction. Cutting tool path and distribution of analysis points are shown in Fig. 1. Points 0 to 8 are arranged in clockwise order and equal angle with each other. Because of the cutting width of the six cases in Table 1 is smaller than the tool diameter, cutting width is distinguished by solid lines.

In order to accurately compare down-milling and up-milling, pure down-milling points and pure up-milling points were used for comparison. As is known to all, there are both down-milling points and up-milling points in the processing area. According to the definition of milling, the feed direction is the same as the rotation direction of the cutting tool when down-milling; otherwise, it is called up-milling. Therefore, just points 5 to 8 meet the requirement in Fig. 1

When extracting the residual stresses of the sub-surface, each point extracted 20 times in the depth direction and the interval is $50 \mathrm{um}$. The residual stress tends to zero at this depth. In order to reduce the error, multiple tool paths are used to extract the residual stresses, and then calculate the average value. In this paper, the residual stresses in feed direction( $\mathrm{x})$ and vertical feed $\operatorname{direction}(\mathrm{y})$ is discussed. 


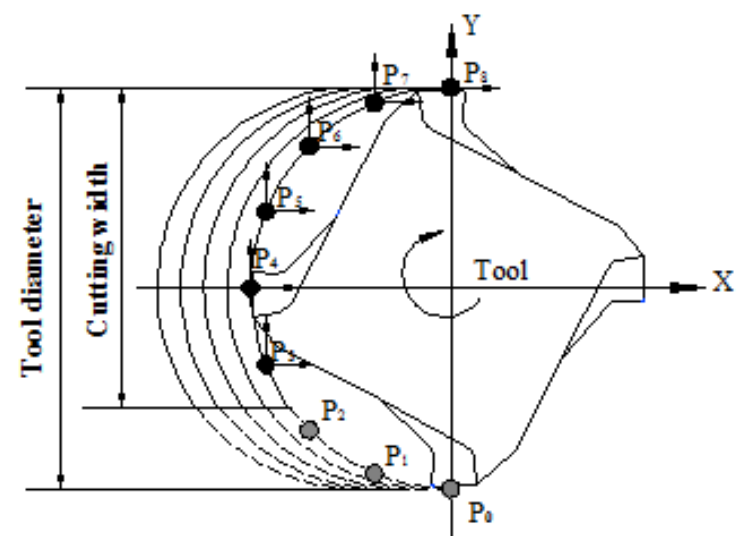

Fig. 1 Cutting tool path and distribution of analysis points

The effects of milling mode on residual stress. The Surface and sub-surface residual stresses and depth of down-milling and up-milling are shown in Table 2. Residual tensile stress $\left(\sigma^{+}\right)$and stress range of points 5 to 8 are used for analysis and comparison. Stress range is equal to the maximum tensile stress minus the maximum compressive stress.

As shown in Table 2, in case 1, 2, 3(low-speed), the tensile stresses and stress range of up-milling in the two directions are smaller than the corresponding values of down-milling. However, in case 4, 5, 6(high-speed), there are a few data of up-milling larger than down-milling. It shows that up-milling is better than that down-milling under low-speed, but in the high-speed, there is no obvious difference between down-milling and up-milling. This reason is that the contact time of tool and chip in down-milling is longer than the time in up-milling under low-speed. Therefore, the heat in the workpiece of down-milling is more than up-milling, which results in residual tensile stresses of down-milling higher than that of up-milling at low-speed. In high-speed milling, chip takes a lot of heat away so that there is no obvious difference between them.

Table 2 Surface and sub-surface residual stresses and depth of different milling modes

\begin{tabular}{|c|c|c|c|c|c|c|c|c|c|}
\hline \multirow{3}{*}{ Case } & \multirow{3}{*}{ statistics } & \multicolumn{4}{|c|}{ Down-milling } & \multicolumn{4}{|c|}{ Up-milling } \\
\hline & & \multicolumn{2}{|c|}{$\begin{array}{c}\text { Feed } \\
\text { direction }(\mathrm{x})\end{array}$} & \multicolumn{2}{|c|}{$\begin{array}{l}\text { Vertical feed } \\
\text { direction(y) }\end{array}$} & \multicolumn{2}{|c|}{$\begin{array}{c}\text { Feed } \\
\text { direction }(\mathrm{x})\end{array}$} & \multicolumn{2}{|c|}{$\begin{array}{l}\text { Vertical feed } \\
\text { direction(y) }\end{array}$} \\
\hline & & $\sigma^{+}$ & $\begin{array}{l}\text { Stress } \\
\text { range }\end{array}$ & $\sigma^{+}$ & $\begin{array}{l}\text { Stress } \\
\text { range }\end{array}$ & $\sigma^{+}$ & $\begin{array}{l}\text { Stress } \\
\text { range }\end{array}$ & $\sigma^{+}$ & $\begin{array}{l}\text { Stress } \\
\text { range }\end{array}$ \\
\hline \multirow{3}{*}{1} & Maximum[MPa] & 185.5 & 376.5 & 207.5 & 373.5 & 101.5 & 213.5 & 161.5 & 309.5 \\
\hline & Mean[MPa] & 106 & 200.5 & 108.6 & 184.5 & 67.1 & 129.4 & 79.4 & 144.1 \\
\hline & Stress depth[mm] & \multicolumn{2}{|c|}{0.65} & \multicolumn{2}{|c|}{0.55} & \multicolumn{2}{|c|}{0.9} & \multicolumn{2}{|c|}{0.6} \\
\hline \multirow{3}{*}{2} & Maximum[MPa] & 223.5 & 375 & 214.5 & 340.5 & 123.5 & 225 & 130 & 224 \\
\hline & Mean[MPa] & 108.0 & 229.1 & 132.9 & 205.6 & 79.3 & 123.1 & 85.3 & 124.1 \\
\hline & Stress depth[mm] & \multicolumn{2}{|c|}{0.65} & \multicolumn{2}{|c|}{0.6} & \multicolumn{2}{|c|}{0.9} & \multicolumn{2}{|c|}{0.65} \\
\hline \multirow{3}{*}{3} & Maximum $[\mathrm{MPa}]$ & 167 & 305.5 & 161.5 & 254 & 119 & 243.5 & 147 & 247 \\
\hline & Mean[MPa] & 99.5 & 161.3 & 84.6 & 145.8 & 60.9 & 145.1 & 78.4 & 137.8 \\
\hline & Stress depth[mm] & \multicolumn{2}{|c|}{0.95} & \multicolumn{2}{|c|}{0.75} & \multicolumn{2}{|c|}{1.2} & \\
\hline \multirow{3}{*}{4} & Maximum[MPa] & 246 & 449 & 269 & 421 & 218.5 & 417 & 294 & 480.5 \\
\hline & Mean[MPa] & 152.3 & 252.5 & 158.3 & 226.5 & 122.8 & 208.9 & 155.5 & 242.4 \\
\hline & Stress depth[mm] & \multicolumn{2}{|c|}{0.55} & \multicolumn{2}{|c|}{0.5} & \multicolumn{2}{|c|}{0.65} & \multicolumn{2}{|c|}{0.55} \\
\hline \multirow{3}{*}{5} & Maximum[MPa] & 229.5 & 405 & 259 & 404.5 & 249.5 & 424.5 & 242 & 348.5 \\
\hline & Mean[MPa] & 142.1 & 211.3 & 144.9 & 194.8 & 158.1 & 231.3 & 150.3 & 212.9 \\
\hline & Stress depth[mm] & \multicolumn{2}{|c|}{0.65} & \multicolumn{2}{|c|}{0.55} & \multicolumn{2}{|c|}{0.65} & \multicolumn{2}{|c|}{0.55} \\
\hline \multirow{3}{*}{6} & Maximum[MPa] & 158.5 & 369.5 & 173.5 & 359.5 & 130.5 & 203.5 & 218 & 304.5 \\
\hline & Mean[MPa] & 121.9 & 192.6 & 121.5 & 175.3 & 92.6 & 144 & 117.6 & 157.4 \\
\hline & Stress depth[mm] & & & & & & & & \\
\hline
\end{tabular}


The effects of milling speed on residual stress. As shown in table 1, The difference between case 1 and case 4 is that the speed is increased and material removal rate increased by 3.5 times, case 2 and case 5, case 3 and case 6 are the same. As shown in table 2, by comparing the 3 pairs of comparison groups, it can be observed that the residual tensile stress and stress range respectively increase by $46 \%$ and $42 \%$ at largest degree in down-milling, while in up-milling, the increase percentage is 1.15 times and $95 \%$. All of above growth rate is far less than the growth rate of material removal rate. Considering the efficiency and quality, we can conclude that the high-speed machining is superior to the low-speed machining.

In addition, Table 2 presents the depth of sub-surface residual stress. It shows that regardless of down-milling or up-milling under high-speed (case 4, 5,6), the depth in two directions are smaller than that in low-speed (case 1,2,3). The reason is that the high temperature generated by the high-speed machining on the workpiece surface does not quickly spread to the interior of the workpiece, which resulting in a smaller depth of the residual stress. The above also reflects that the high-speed machining is superior to the low-speed machining.

Process parameters optimization. As shown in table 2, by observing both the tensile stresses and stress range of the two directions, the smaller residual stresses are obtained in case 3 under low-speed milling(case 1, 2, 3) and under high-speed milling(case 4, 5, 6), case 6 obtains the smaller residual stresses. That is to say, when the material removal rate is constant, the smaller cutting width with larger cutting depth can reduce the residual stresses.

\section{Experiments and analysis of results}

The experiments have conducted at five-axis machining center of DECKEL MAHO's DMU60P. The workpiece material is Al7050-T7451 and the size is $100 \mathrm{~mm} \times 80 \mathrm{~mm} \times 10 \mathrm{~mm}$. The tool material and parameters are consistent with the simulation.

The processing parameters of case 1 and case 4 in table 1 were chosen to carry out experiments on different milling modes. The machined surface residual stresses were measured with Canada PROTO-LXRD X-Ray Stress analyzer. It can manually set the rotation angle of the working table to measure the residual stresses in feed and vertical direction. The location and number of points measured in experiments was 5 to 8, as shown in Fig. 1.

Fig. 2 is a comparison between the simulation and experiments on distribution law of residual stress in different modes and material removal rate. Fig. 2 (a) is the simulation and experiment comparison of case 1, Fig. 2 (b) is the simulation and experiment comparison of case 4 . It shows that the trend of residual stress curves under simulation and experiments is similar. The curves show a downward trend. The reason is that the cutting thickness decreases gradually from point 5 to 8 , resulting in Extrusion effect tool and workpiece increases. Therefore, the tensile stress gradually changes to the compressive stress. By observing experimental data of Fig. 2 (a), the residual stresses in vertical feed direction(y) under up-milling is slightly higher than that under down-milling, but the residual stresses in feed direction(x) under up-milling is far less than that under down-milling. It still shows that up-milling is better than down-milling in low-speed under comprehensive consideration. By observing experimental data of Fig. 2 (b), there is no obvious difference between up and down milling. The conclusions of the experiments are consistent with the conclusions of simulation. As shown in Fig. 2, the experimental value is smaller than in the simulation. The reason of error may be that initial residual stress of the workpiece is not taken into account in the simulation. 

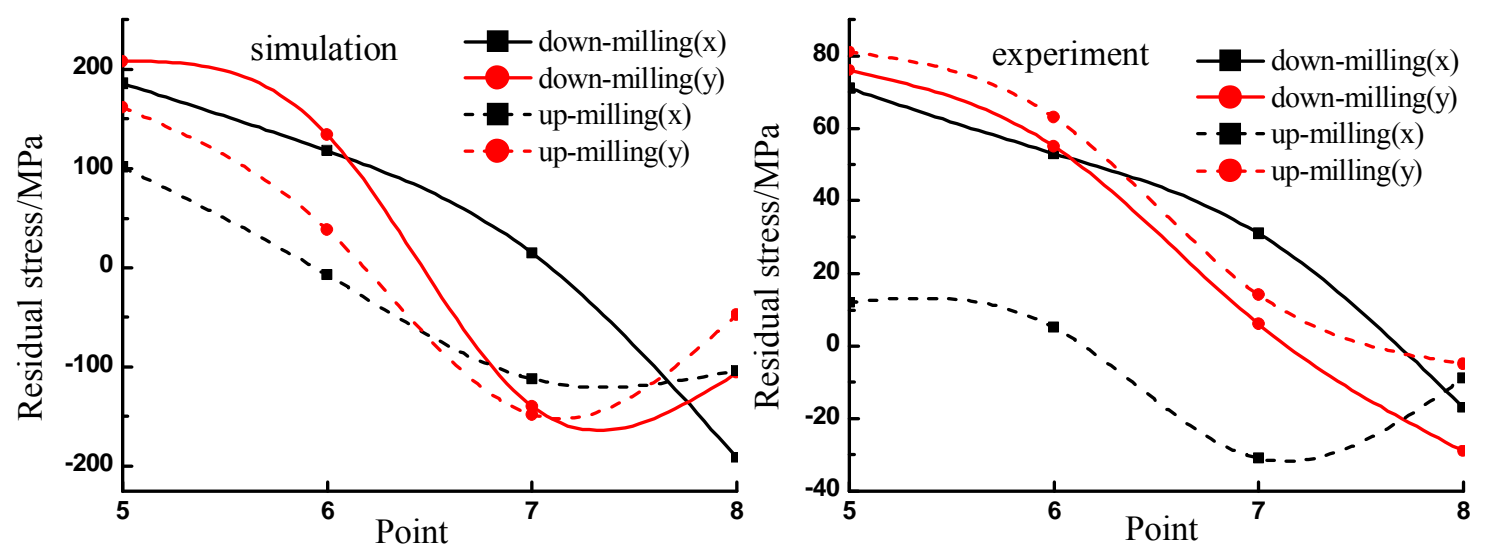

(a) n=4000rpm, f=0.8mm $/ \mathrm{rev}, \quad \mathrm{ae}=10 \mathrm{~mm}, \quad$ ap $=0.12 \mathrm{~mm}, \mathrm{Q}^{\prime} \mathrm{w}=3480 \mathrm{~mm}^{3} / \mathrm{min}$
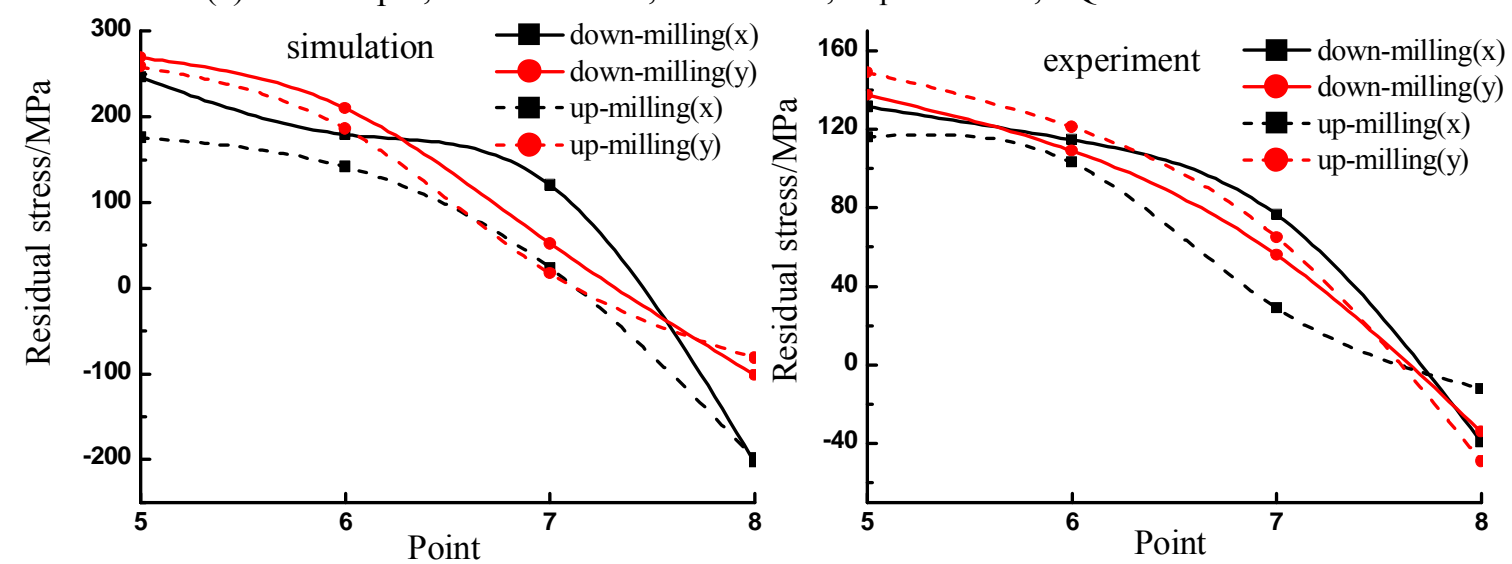

(b) $\mathrm{n}=18000 \mathrm{rpm}, \quad \mathrm{f}=0.8 \mathrm{~mm} / \mathrm{rev}, \quad \mathrm{ae}=10 \mathrm{~mm}, \quad$ ap $=0.12 \mathrm{~mm}, \quad \mathrm{Q}^{\prime} \mathrm{w}=17280 \mathrm{~mm}^{3} / \mathrm{min}$

Fig. 2 Distribution law of residual stress in different modes and material removal rate

\section{Conclusions}

By analyzing simulation and experimental results of different milling modes and process parameters, the following conclusions can be drawn.

(1) Due to the limitation of the simulation assumptions and parameters, the simulation and the experimental results have some differences on magnitude of data, but the influence of the milling modes and process parameters on the residual stress is similar, and it has theoretical significance and practical reference value for planning experiment.

(2) Up-milling is better than down-milling in low-speed and there is no obvious difference between them in high-speed.

(3) Better processing quality and higher production efficiency can be effectively achieved in high-speed milling. For example, residual tensile stress and stress range respectively increase by $46 \%$ and $42 \%$ at largest degree, while material removal rate increase by 3.5 times.

(4) When the material removal rate is constant, decreasing cutting width and improving cutting depth can obtain smaller residual stresses.

The above conclusions can not only lay a good theoretical and technological foundation for the construction of process parameters optimization criterion, but also can choose the suitable milling modes and process parameters according to the actual machining target and machine, etc.

\section{Acknowledgements}

This project was supported by National Nature Science Foundation (No.51175077). 


\section{References}

[1] Coto B, Navas VG, Gonzalo O, et al. Influences Of Turning Parameters In Surface Residua Stresses In Aisi 4340 Steel[J]. International Journal of Advanced Manufacturing Technology, 2011, 53(9-12): 911-920.

[2] Capello E. Residual stresses in turning: Part I: Influence of process parameters[J]. Journal of Materials Processing Technology, 2005, 160(2):221-228.

[3] Ee K C, Dillon O W, Jawahir I S. Finite element modeling of residual stresses in machining induced by cutting using a tool with finite edge radius[J]. International Journal of Mechanical Sciences, 2005, 47(10):1611-1628.

[4] Thiele J D, Melkote S N. Effect of Tool Edge Geometry on Workpiece Subsurface Deformationand Through-Thickness Residual Stresses for Hard Turning of AISI 52100 Steel[J]. Journal of Manufacturing Processes, 2000, 2(4):270-276.

[5] Jiang X H, Li B Z, Zuo X Y, et al. Processing Parameters Optimization on Control of Residual Stresses and Distortion during High-Speed Milling of Thin-Walled Workpiece[J]. Key Engineering Materials, 2013, 531-532:118-121.

[6] Jiang X H, Li B Z, Yang J G, et al. Research on the Properties of Milling and the Process Parameters Optimization for Aluminum-Alloy Thin-Walled Parts[J]. Applied Mechanics \&Materials, 2011, 44-47:2842-2846. 